\title{
The Impact of Computer Mediated Communication (CMC) on Productivity and Efficiency in Organizations: A Case Study of an Electrical Company in Trinidad and Tobago
}

\author{
Kenrick Bob'1, Prahalad Sooknanan ${ }^{2}$ \\ ${ }^{1}$ Arthur Lok Jack Graduate School of Business, University of the West Indies, Mt. Hope, Trinidad and Tobago \\ ${ }^{2}$ University of Trinidad and Tobago, O'Meara Campus, Arima, Trinidad and Tobago \\ Email: Prahalad.sooknanan@utt.edu.tt
}

Received 5 April 2014; revised 10 May 2014; accepted 18 May 2014

Copyright (C) 2014 by authors and Scientific Research Publishing Inc.

This work is licensed under the Creative Commons Attribution International License (CC BY). http://creativecommons.org/licenses/by/4.0/

(c) (i) Open Access

\section{Abstract}

This study investigates how computer mediated communication (CMC) and the electronic mailing system in particular have impacted on productivity and efficiency not to mention interpersonal interaction and increased use of technology in the organization. An electricity company was chosen for the case study since it had achieved approximately $78 \%$ computerization and networking of its office staff. Following the judgemental sampling technique to identify the organization, random sampling was used to select a sample size of 100 respondents. A questionnaire survey with sixteen items was self-administered over a one-week period. The results showed that $73 \%$ of the respondents agreed that CMC enhanced their overall productivity and efficiency while $27 \%$ differed. However, while the findings revealed that the introduction of CMC increased its use as a whole, it impacted negatively on interpersonal relationships among respondents.

\section{Keywords}

Computer Mediated Communication (CMC), Interpersonal Interaction, Productivity and Efficiency, Technology in Organizations 


\section{Introduction}

Technology plays a major role in all human cultures and societies, from the first group of humans who domesticated fire to be used as a weapon and a tool to the development of the light bulb that sparked the age of electrification to the development of the computer and the Internet that resulted in our present information age (Green, 2002). To this end, Rogers (1986) claimed that the microcomputer is one of the most important innovations of recent decades in terms of its impact in homes, schools and businesses. The Internet, in particular, was the catalyst that catapulted the computer into a global phenomenon. It was estimated that in 2002 there were 544 million users of the Internet international (Rogers, 2003) and that number is growing exponentially.

One of the biggest users of computers and computer networks is the business environment. Most companies have local and wide area networks that link individual computers from the same location and multiple locations to each other so that information and messages can be shared. These computer networks are then linked via the Internet to the World Wide Web making it easier to communicate with suppliers, clients and business partners.

In the modern workplace there is a computer at every desk with each networked to form part the company's local or wide area network. From each terminal, electronic mail otherwise known as e-mail, can be sent to single as well as multiple recipients thus making the distribution of information easier and quicker than ever before. Managers believe that access to and use of this information would result in increased worker productivity and efficiency and make it easier for them to communicate with staff.

Due to the effects of globalization, local businesses must now compete globally for market dominance and this puts increase demands on businesses to ensure that productivity and efficiency are at a high level and continually improving. This study will, therefore, assist in evaluating whether computer mediated communication $(\mathrm{CMC})$ increases worker productivity and efficiency. In addition, it will also identify any negative effects as a result of implementing CMC.

To this end, the study is aimed at determining how CMC affects the organization in the following ways:

- Workers' productivity and efficiency;

- Workers' interpersonal interactions;

- Workers' usage of new technology.

The investigation was conducted using an electricity company in Trinidad and Tobago as a case study. The company was chosen based on the fact that it had attained a $78 \%$ computerization and networking of its office staff with plans to be fully computerized by 2010 . To achieve the objectives of the study, the researchers posed the following research question: Does CMC, such as e-mail, improve the productivity and efficiency of the organization?

The potential outcomes of the study were that workers' productivity and efficiency will generally increase, interpersonal interaction will generally decrease, and workers' usage of new technology will be varied based on age, gender and educational level.

\section{Literature Review}

According to Rogers (1986), the development of human communication technologies can be divided into four main eras. Firstly, there was the writing era of communication which began approximately in 4000 before Christ (B.C.) and can be traced to writings on Sumerian clay tablets. This was followed by the printing era of communication which began in 1456 A.D. with the invention of the first movable printing press by Johann Gutenberg. The telecommunication era began in 1844 A.D. with the invention of the telegraph and the transmitting of the first message by Samuel Morse. One important function of this era was that it provided a means to move ideas to people instead of moving people to ideas. Lastly, the interactive communication era began in 1946 A.D. with the invention of the first mainframe computer. This communication technology eventually made possible person-toperson interactive communication by the 1980s.

Today, the interactive communication era is having a profound impact on many aspects of life. Individuals to large conglomerates have all adopted this new technology by and large due to the development of the Internet. Rogers (2003) recounts the development of the Internet to 1969 when the ARPANET network was developed to allow thirty US Department of Defense contractors to share computer software and databases. Electronic mail was added as an afterthought but soon became the main function for the network users. By the late 1980s, ARPANET and other existing computer networks were merged to form the Internet. The diffusion of this technology started out slowly but after approximately eighteen years, its adoption made an exponential rise to where 
it is today. In 1995, there were approximately 20 million computers connected on the Internet with that number doubling every year until it reached approximately 544 million in 2002.

Computer mediated communication (CMC) encompasses all forms of communication facilitated by the use of the personal computer. In the workplace, CMC improved the information processing systems. Research in this area showed that CMC resulted in a more efficient flow of information up, down and across organizations (Rogers, 1986) and created greater access to organizational power, decision-making and creative processes (Kiesler, Siegel, \& McGuire, 1984). It has also been credited with significant improvement in task efficiency, planning, promoting timely and complete feedback, controlling organizational activities, managing time, initiating action plans, responding to the environment, planning flexible work schedule, eliminating manual labor, composing and preparing written documents (Rice \& Blair, 1984).

Research in the social and psychological impact of CMC in the workplace show that group dynamics changed; members participated more equally and high status members did not dominate the interaction to the same degree as in face-to-face meetings (Kiesler, Siegel, \& McGuire, 1987). This happened because CMC filters out certain personal, social and behavioral cues, such as voice and body language that people use in face-to-face communication. According to Berry (2004), the four main advantages of CMC, which is a type of asynchronous communication media, over face-to-face communication or synchronous communication media include more active and equal team member participation, flexibility over time and distance combined with ease of changing team size quickly, the ability of team members to reflect or collect data before responding, and instant and evolving archived records of the discussion known as threading. On the other hand, the technical nature of CMC contributes to many negative outcomes such as depersonalization, impoliteness, information overload and increase worker stress due to having to respond quickly.

One of the ways different communication media are evaluated is by means of media "richness". Media "richness" is defined as the ability of different media to convey messages that communicate rich information. "Richness" is the capacity to share meaning (Daft \& Lengel, 1984). Communication channels can be arranged in a continuum with face-to-face being the richest because it gives the greatest possibility of the sender and receiver sharing meaning (Waldvogel, 2001). Although CMC lacks some of the key components of "rich" channels such as multiple cues, personal focus and language variety do convey "rich" information, it is suggested that this is possible because recipients interpret messages based on a number of factors such as:

- Integrating e-mail with other knowledge;

- Individuals use their own knowledge of organizational processes and procedures;

- The organizational recipient sender-relationship;

- Message header information;

- Message type;

- Threads of conversation;

- The recipient role in the organization Williams (1999).

Notwithstanding these mitigating factors, this study attempts to determine the media "richness" or impact of $\mathrm{CMC}$ on the productivity and efficiency of employees not to mention interpersonal relationships and technology usage.

\section{Setting and Context}

The investigation was conducted among employees in an electrical company in Trinidad and Tobago as a case study. The company is one of two state-owned electric utilities. Its mission statement is to "Provide the public with a reliable, safe and adequate supply of electricity in the most efficient manner and at prices required by law to meet both the present and future social and economic needs of the Republic of Trinidad and Tobago".

The company has a total of 2488 employees. The executives, managers, administrative and the professional staff make up approximately 1235 employees of whom 962 have access to a networked computer. This is approximately $78 \%$ of the total office staff.

In the early 1990s computers were still quite expensive and the organizational policy was for computers to be given to executives/managers and professional staff with other administrative staff having to use manual systems or inherit the old "hand me down" from the managerial and professional staff. The organization soon realized that computers were essential for its administrative staff who made most of the data entries in databases and other software packages that were required by managers and professionals in order to make sound business de- 
cisions.

By the mid-1990s, however, computers were placed on almost every desk so that information can move up, down and across the organization more quickly. This resulted in computer software application training being conducted at all levels in the organization by external and internal trainers.

\section{Methodology}

In this study, judgemental sampling was used to select the organization for the case study from all the other large companies in Trinidad and Tobago and random sampling was used to determine the sample size from the population of employees. The minimum sample size was calculated using the following equation by Saunders, Lewis and Thornhill (2003):

$$
n=p \% \times q \% \times(z / e \%)^{2}
$$

$n$ is the minimum sample size required.

$p \%$ is the portion belonging to the specified category.

$q \%$ is the portion not belonging to the specified category.

$z$ is the value corresponding to the level of confidence required.

$e \%$ is the margin of error required.

From the total population of employees, the following factors were determined:

$p \%$ represents the $\%$ of employees that have an opinion about the effects of CMC. This factor is estimated at $80 \%$.

$q \%$ represents the \% of employees that do not have an opinion about CMC. This factor is estimated at $20 \%$.

$z$ was chosen as 1.96 which correspond to a confidence level of $95 \%$.

$e \%$ was chosen as $5 \%$.

$n$ is approximately 246 employees.

Since the population is less than 10,000 , the sample size was further adjusted. The adjusted minimum sample size, $\boldsymbol{n}^{\prime}$, is:

$$
n^{\prime}=\frac{n}{1+(n / N)}
$$

$N$ is the total population of 962 employees.

$\boldsymbol{n}^{\prime}$ is 195 employees.

The most scientific way to proceed with this research was to randomly select 195 employees. However, due to time constraints the sample size of 100 employees was randomly chosen for the questionnaire survey.

The questionnaire was composed of structured questions keeping in mind the objectives of the study. The questions were short and clear. The response choices were also clear and well defined so that participants could choose one definite answer. The choice options of "other", "sometimes" and "somewhat" were also included to ensure accurate data collection and interpretation. The questionnaire was made attractive by grouping the questions and giving them headings.

Questions 1 - 6 under the heading Background are attribute type questions that relate to demographics of the participants and were asked in an effort to support the objective of workers usage of new technology. A worker's usage of new technology was expected to be varied based on age, gender and educational background.

Questions 7 - 9 under the heading Access and Use of e-mail sought to determine whether participants access to the Internet or Intranet actually made use of e-mail. Question 9 highlighted a number of reasons as to why e-mails may be used. Participants were encouraged to choose as many options as possible as they seemed relevant.

Questions 10 - 16 under the heading Advantages and Disadvantages of e-mails investigated the other two objectives in terms of workers interpersonal interactions and productivity and efficiency. Participants were asked these questions directly in items 13 and 14 respectively. Questions $10-12$ were asked to determine which method of communication persons prefer and their reasons. Questions 15 and 16 were less structured and gave participants an opportunity to express themselves freely on the use of e-mail.

\section{Data Analysis}

The questionnaire was randomly distributed to 100 employees from five different departments of various ages, 
gender and educational level (see Appendix II for summary results). There were 68 respondents made up of 36 men $(52 \%)$ and 32 women (48\%). The data were analyzed based on the three stated objectives.

The first objective dealt with the effect CMC has on worker productivity and efficiency. The questionnaire revealed that $70 \%$ of the respondents felt that workers' productivity and efficiency increased significantly with the use of e-mail as a form of communication. They highlighted a number of ways in which they currently use e-mails to increase their productivity and efficiency as follows:

- Contact persons not easily contactable;

- Keep proof of messages sent;

- Reinforce messages;

- Data transfer and access from different locations;

- Saves time-speed;

- Less paper-files stored electronically;

- Same data can be sent to multiple users;

- Corresponding especially with foreign suppliers;

- Reduce phone tagging;

- Keep current with changes and new ideas.

Only $3 \%$ of the respondents reported a marginal increase in their productivity and efficiency with the use of e-mail while $27 \%$ felt that e-mail has not increased their productivity and efficiency. Some of the reasons given were:

- E-mails are taken for granted as persons do not access their mail in a timely and urgent manner, this results in delays in getting a response;

- Lack of security on sensitive documents;

- Too much junk mail;

- Abuse of facility for entertainment;

- Impersonal relationship destroyed;

- Distracting;

- Information overload;

- Send information to wrong persons - same name.

However, all the respondents admitted that they use e-mail at present.

The second objective dealt with the effects of CMC on the interpersonal interaction of workers. The majority of respondents (56\%) reported that e-mail decreased the interpersonal interaction of workers while $44 \%$ claimed that CMC did not affect interpersonal interaction of workers.

The third objective dealt with how workers usage of new technology would be affected by age, gender and educational background. Table 1 highlights the respondents preferred method of communication based on age. It shows that in the lowest age group of $18-25$ years, none of the respondents chose e-mail as the preferred choice of communication. However, it highlights a sharp increase to $33 \%$ from the respondents in age group 26 35 years choosing e-mail as their preferred choice of communication. It also shows that there is continuous decline in the use of e-mail as a preferred choice of communication as the age group gets older. Thirty percent of the respondents from the age group 36 - 45 years chose e-mail compared to $20 \%$ of the respondents from age group $46-55$ years. This is illustrated in Table 1 and Figure 1.

Figure 2 shows the respondents preferred communication method based on gender. It reveals that $31 \%$ of women and $22 \%$ of men prefer to use e-mail than other forms of communication.

Table 1. Respondents preferred communication method based on age.

\begin{tabular}{ccccc}
\hline \multirow{2}{*}{ Age of respondents (yrs) } & \multicolumn{3}{c}{ Preferred communication method (\%) } \\
\cline { 2 - 5 } & E-mail & Telephone & Face-to-face & No response \\
\hline $18-25$ & $0 \%$ & $75 \%$ & $25 \%$ & $0 \%$ \\
$26-35$ & $33 \%$ & $13 \%$ & $47 \%$ & $7 \%$ \\
$36-45$ & $30 \%$ & $30 \%$ & $30 \%$ & $10 \%$ \\
$46-55$ & $20 \%$ & $20 \%$ & $60 \%$ & $0 \%$ \\
\hline
\end{tabular}


Figure 3 shows the preferred communication method based on educational level. The options of undergraduate and postgraduate were combined under one heading, Degree. The category Diploma/Associate degree was simply labeled as diploma on Figure 3. Figure 3 shows that $40 \%$ of the respondents with degrees prefer to use e-mails as their preferred choice of communication. Nineteen percent of the respondents with diploma/associate degree chose e-mail as their preferred choice, and no one with secondary education chose e-mail as a preferred choice of communication.

\section{Summary and Conclusions}

The objective of this research paper was to determine how computer mediated communication (CMC) such as e-mail has impacted the organization in the following ways:

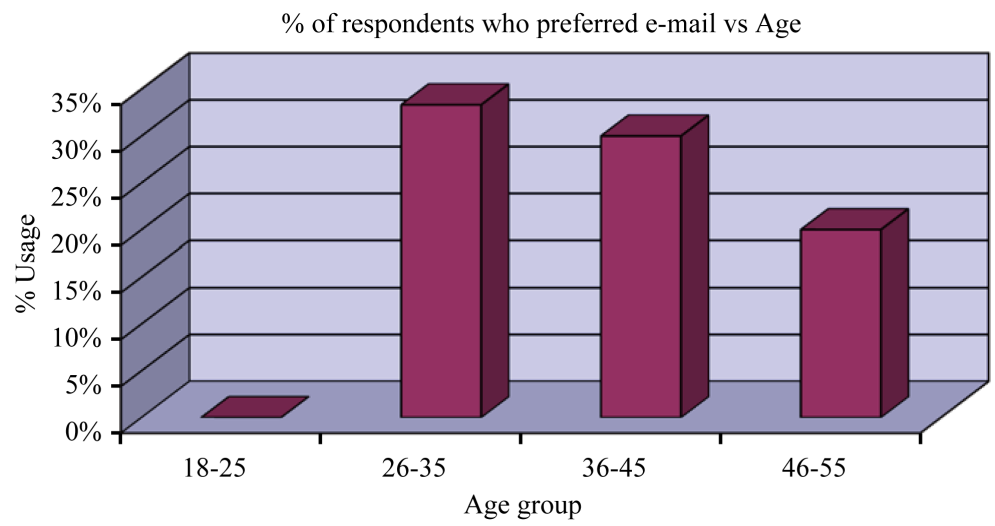

Figure 1. CMC usage of respondents' based on age.

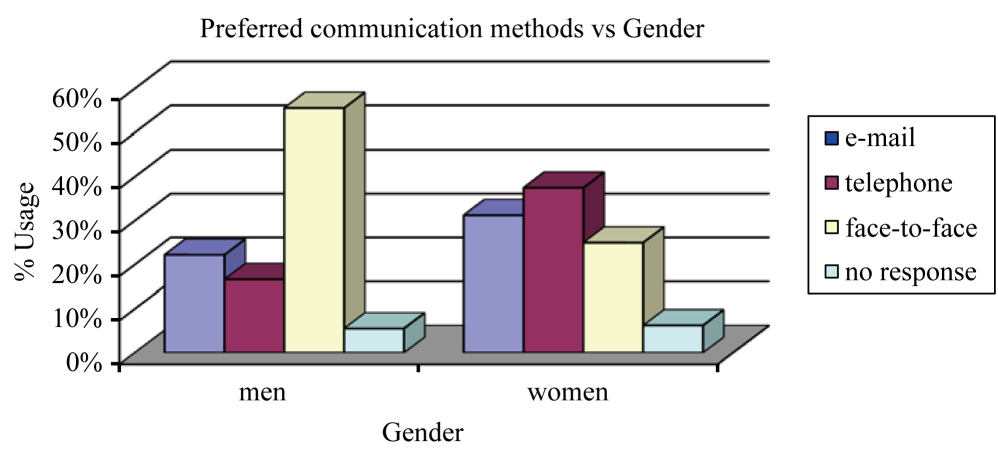

Figure 2. Responses to preferred communication method based on gender.

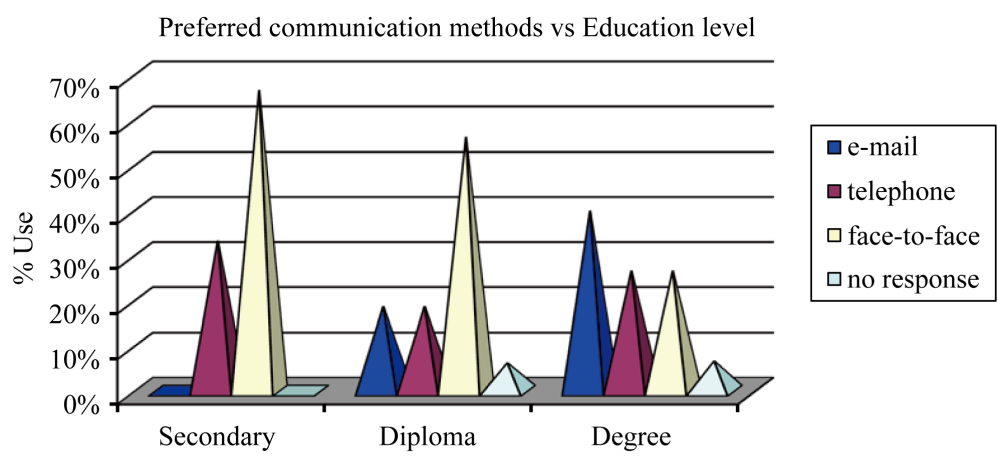

Level of Education

Figure 3. Respondents' preferred communication method based on educational level. 
- Workers' productivity and efficiency;

- Workers' interpersonal interactions;

- Workers' usage of new technology.

Based on the findings, $73 \%$ of the respondents felt that their productivity and efficiency increased or increased somewhat and $27 \%$ felt that their productivity and efficiency had not increased. It is, therefore, evident that the majority of employees felt that CMC had increased productivity and efficiency in the workplace. On the other hand, the findings revealed that $56 \%$ of the respondents agreed that CMC decreased interpersonal interaction among workers. This was highlighted as one of the negative consequences of CMC. Further, $44 \%$ of respondents felt that CMC did not affect interpersonal interaction of employees at all.

Workers' usage of CMC was dependent on age, gender and education background. The findings revealed that as the age of the respondents increased from 26 years to 55 years, there was a decrease in the usage of CMC from $33 \%$ to $20 \%$. Surprisingly, the respondents for the age group $18-25$ years did not choose CMC as their preferred communication method. This trend is shown in Table 1 and Figure 1 respectively.

There was a definite increase in the percentage of women who preferred CMC to men. This can be observed in Figure 2 where $31 \%$ of the women as compared to $22 \%$ of the men preferred CMC to other communication methods. Further, it was interesting to note that as the respondents' education level increased, there was a corresponding increase in $\mathrm{CMC}$ as the preferred communication method as shown in Figure 3.

Generally, the findings are consistent with the literature that suggests that the use of CMC would result in an improvement in the information processing system within an organization. With regards to the organization under study, it was observed that the introduction of CMC contributed to substantial improvement in productivity and efficiency, which was identified by the majority of the respondents. As a result, the findings of the study demonstrate that $\mathrm{CMC}$ is the preferred method of communication necessary to enhance upward, downward and lateral communication and especially general usage of the technology in the organization. CMC, therefore, has the potential to provide organizations as a whole with the competitive edge in today's increasingly competitive business environment.

\section{References}

Berry, G. R. (2004). Lessons from the Online Teaching Experience. Journal of the Academy of Business Education, 5, 88-97.

Daft, R. L., \& Lengel, R. (1984). Information Richness: A New Approach to Managerial Behavior and Organizational Design. Greenwich, CT: JAI Press.

Green, L. (2002). Communication, Technology and Society. London: Sage Publication Ltd.

Kiesler, S., Siegel, J., \& McGuire, T. W. (1984). Social Psychological Aspects of Computer-Mediated Communication. American Psychologist, 39, 1123-1134. http://dx.doi.org/10.1037/0003-066X.39.10.1123

Rice, R. E., \& Blair, T. H. (1984). New Organizational Media and Productivity Beverly Hills. Thousand Oaks, CA: Sage.

Rogers, E. M. (1986). Communication Technology the New Media in Society. New York: The Free Press.

Rogers, E. M. (2003). Diffusion of Innovations (5th ed.). New York: The Free Press.

Saunders, M., Lewis, P., \& Thornhill, A. (2003). Research Methods for Business Students (3rd ed.). England: Prentice Hall.

Waldvogel, J. (2001) Email and Workplace Communication: A Literature Review: Language in the Workplace Occasional Papers Number 3. New Zealand: Victoria University of Wellington.

Williams, E. (1999). E-Mail and the Effect of Future Developments. First Monday, 4. http://www.firstmonday.dk/issues/issue4_8/williams/

http://dx.doi.org/10.5210/fm.v4i8.686 